\title{
(a) Efficacy of interventions for adherence to the immunosuppressive therapy in kidney transplant recipients: a meta-analysis and systematic review
}

\author{
Yichen Zhu, ${ }^{1,2}$ Yifan Zhou, ${ }^{3}$ Lei Zhang, ${ }^{1,2}$ Jian Zhang, ${ }^{1,2}$ Jun Lin ${ }^{1,2}$
}

\begin{abstract}
'Department of Urology, Capital Medical University Beijing Friendship Hospital, Beijing, China

${ }^{2}$ Beijing Key Laboratory of Tolerance Induction and Organ Protection in Transplantation, Beijing, China

${ }^{3}$ National Institute of Diabetes and Digestive and Kidney Diseases, Bethesda, Maryland, USA
\end{abstract}

Correspondence to Dr Jun Lin, Department of Urology, Capital Medical University Beijing Friendship Hospital, No.95 Yong'an Road, Xicheng District, Beijing 100050,China; linjun@medmail.com.cn

Accepted 13 April 2017 Published Online First 4 May 2017

Copyright () 2017 American Federation for Medical Research
CrossMark

To cite: Zhu Y, Zhou Y,

Zhang L,etal. JInvestig Med 2017;65:1049-1056.

\begin{abstract}
Immunosuppressive treatment regimens are complex and require ongoing self-management. Medication adherence can be difficult to achieve for several reasons. The current meta-analysis and systematic review investigated whether adherence interventions improved immunosuppressive treatment adherence in kidney transplant recipients. Medline, Cochrane, EMBASE, and Google Scholar were searched until October 17, 2016 using the following search terms: kidney transplantation, compliance, adherence, and immunosuppressive therapy. Randomized controlled trials and two-arm prospective, retrospective, and cohort studies were included. The primary outcomes were adherence rate and adherence score. Eight studies were included with a total for 546 patients. Among participants receiving intervention, the adherence rate was significantly higher than the control group (pooled $\mathrm{OR}=2.366,95 \% \mathrm{Cl} 1.222$ to $4.578, p=0.011$ ). Participants in the intervention group had greater adherence scores than those in the control group (pooled standardized difference in means $=1.706,95 \% \mathrm{Cl} 0.346$ to $3.065, \mathrm{p}=0.014$ ). Sensitivity analysis indicated that findings for adherence rate were robust. However, for adherence score, the significance of the association disappeared after removing one of the studies indicating the findings may have been overly influenced by this one study. Intervention programs designed to increase immunosuppressive adherence in patients with kidney transplant improve treatment adherence.
\end{abstract}

\section{INTRODUCTION}

In the past decades, immunosuppressive drugs and improved surgical techniques have increased the 1-year graft survival in kidney transplantation; however, the 10-year kidney transplant function remains low $(50 \%) .{ }^{1}$ One reason for the lack of improvement in longterm outcomes is poor adherence to immunosuppressive therapy. ${ }^{2}$ Up to $60 \%$ of late acute rejection and about $30-35 \%$ of graft loss is due to non-adherence. ${ }^{3-5}$ The rate of nonadherence in patients with kidney transplant ranges from $15 \%$ to $55 \% .{ }^{6-9}$ Prior studies have found that non-adherence to medications leads to suboptimal outcomes and has been seen in

\section{Significance of this study}

What is already known about this subject?

- About $60 \%$ of late acute rejection and $30-35 \%$ of graft loss is due to non-adherence.

- In addition, the rate of non-adherence in patients with kidney transplant ranges from $15 \%$ to $55 \%$.

- Risk factors for non-adherence include longer time post-transplantation, financial strain, depression, younger age, social isolation, and low cognition.

What are the new findings?

- Among participants receiving adherence intervention, the adherence rate was significantly higher than the control group.

- Participants in the intervention group had greater adherence score than those in the control group.

- In conclusion, this adherence intervention significantly improved adherence to immunosuppressive therapy in patients with kidney transplant.

How might these results change the focus of research or clinical practice?

- Improving adherence to immunosuppressive therapy in patients with kidney transplant is necessary for better prognosis.

- How to measure the adherence in patients with kidney transplant effectively is an important issue.

- Additional studies are necessary to better understand what types of intervention are most effective, and to gain greater insight into the impact of intervention on clinical outcomes.

almost half of graft losses. ${ }^{2} 10 \quad 11$ Nonadherence is associated with decreased graft function, increased risk of kidney loss, and premature death. ${ }^{12}$

Immunosuppressive treatment regimens are complex and require ongoing self-management. 
Medication adherence can be difficult to achieve for several reasons including cost, dosing complexity, duration of treatment, forgetfulness, other priorities, and decision to omit a dose. ${ }^{13}$ In addition, the presence of serious side effects of immunosuppressive treatment and the patient's appraisal of these side effects can impact adherence. ${ }^{14} 15$ These side effects can include Cushingoid appearance, acne, weight gain, increased infection rate, diarrhea, and insomnia. ${ }^{16}$ Risk factors for non-adherence include longer time posttransplantation, financial strain, depression, younger age, social isolation, and low cognition. ${ }^{7}$ 17-20

Several studies have evaluated the methods used to improve adherence of treatment in patients with kidney transplants and improve transplantation outcomes. Interventions such as electronic monitoring feedback and cognitive education have shown benefit in improving adherence. ${ }^{21}$ Other types of interventions are multicomponent and can involve incorporating personalized care planning, education, psychosocial support, decision aids, and self-monitoring tools. ${ }^{22}$ This study investigated whether adherence interventions improve adherence of kidney transplant recipients to immunosuppressive regimens.

\section{METHODS}

\section{Search strategy}

Medline, Cochrane, EMBASE, and Google Scholar were searched up to October 17, 2016 using the following search terms: kidney transplantation, compliance, adherence, and immunosuppressive therapy. Randomized controlled trials (RCTs), two-arm prospective, retrospective, and cohort studies were included. Eligible studies had to have evaluated patients with solitary kidney transplants who were taking maintenance immunosuppressive regimen (s) following transplant surgery. Patients also must have received interventions to promote better adherence. Included studies also had to have reported quantitatively outcomes of interest. Letters, comments, editorials, case reports, proceedings, and personal communications were excluded. The list of potential studies was reviewed by two independent reviewers. In the case of uncertainty regarding eligibility, a third reviewer was consulted.

\section{Data extraction and quality assessment}

The following information/data were extracted from the included studies: the name of the first author, year of publication, study design, number of participants in each group, participants' age and gender, and the major outcomes.

The quality of the included studies was assessed using the Cochrane Collaboration's tool for assessing risk to assess the included studies. ${ }^{23}$

\section{Outcome measures}

The primary outcomes were adherence rate and adherence score. Determination of adherence rate used methods, such as refill records, electronic medical caps that monitored each time the bottle opened, or patient surveys, to monitor drug use. Adherence score predicts a patient's adherence by identifying lapses in patient medication adherence. Adherence score takes into consideration whether the patient took a medication on a given day and if it was taken within a certain time frame.

\section{Statistical analysis}

OR was used as the measure of effect size for adherence rate, while standardized difference in means were used for adherence score. An OR > 1 indicated benefit favoring intervention, and a standardized difference in means of adherence score indicated a beneficial effect for intervention. Study heterogeneity was presented using a $\chi^{2}$-based Cochran's $\mathrm{Q}$ statistic and $\mathrm{I}^{2}$. For the $\mathrm{Q}$ statistic, $\mathrm{p}<0.10$ was considered statistically significant for heterogeneity. For the $\mathrm{I}^{2}$ statistic, $\mathrm{I}^{2}<25 \%$ indicated low heterogeneity while $\mathrm{I}^{2}>75 \%$ indicated high heterogeneity. A DerSimonian-Laird random-effects model was performed to calculate pooled estimates of standardized difference in means across studies. ${ }^{24}$ Leave-one-out sensitivity analyses were performed to evaluate whether any single study might have overly impacted the pooled results. A two-sided $\mathrm{p}<0.05$ was considered significant. All statistical analyses were performed using the statistical software Comprehensive Meta-Analysis, V.2.0 (Biostat, Englewood, New Jersey, USA).

\section{RESULTS}

The database searches identified 109 potential studies (figure 1), of which 60 were excluded due to being duplicates or not being relevant to our analysis. Forty-nine studies underwent full-text review, and 41 were eliminated for not reporting outcomes of interest, not having an adherence intervention, for being an abstract, being an ongoing study, and evaluating patients with liver or kidney transplant.

A total of eight studies were included encompassing 546 patients (ranging from 15 to 130 patients per study) (table 1). ${ }^{25-32}$ Six of the included studies were randomized trials, and the other two studies were prospective. One study reported results for underage population, others recruited patients with the mean age $\geq 40$ years, with a greater percentage of the population being male. The shortest duration of follow-up was 3 months. The intervention protocols used varied across studies (table 1).

\section{Meta-analysis}

Six studies provided information regarding adherence rate and were included in the meta-analysis. No significant heterogeneity among the five studies was observed $(\mathrm{Q}=8.8$, $\left.\mathrm{p}=0.116, \mathrm{I}^{2}=43.4 \%\right)$. The pooled analysis found that among participants receiving adherence intervention, the adherence rate was significantly higher than the control group (pooled $\mathrm{OR}=2.366,95 \% \mathrm{CI} 1.222$ to 4.578 , $\mathrm{p}=0.011$ ) (figure $2 \mathrm{~A}$ ).

Three studies were included in the analysis for evaluation of the effect of intervention on adherence score. Large heterogeneity was observed in the data across studies $\left(\mathrm{Q}=12.3, \mathrm{p}=0.002, \mathrm{I}^{2}=83.8 \%\right)$. The pooled analysis indicated that participants in the intervention group had greater adherence score than those in the control group (pooled standardized difference in means $=1.706,95 \% \mathrm{CI}$ 0.346 to $3.065, \mathrm{p}=0.014$ ) (figure $2 \mathrm{~B}$ ).

\section{Sensitivity analysis}

Sensitivity analysis, in which each study was removed in turn, found that for adherence rate and adherence score, the removal of one study (Garcia et al for adherence rate 

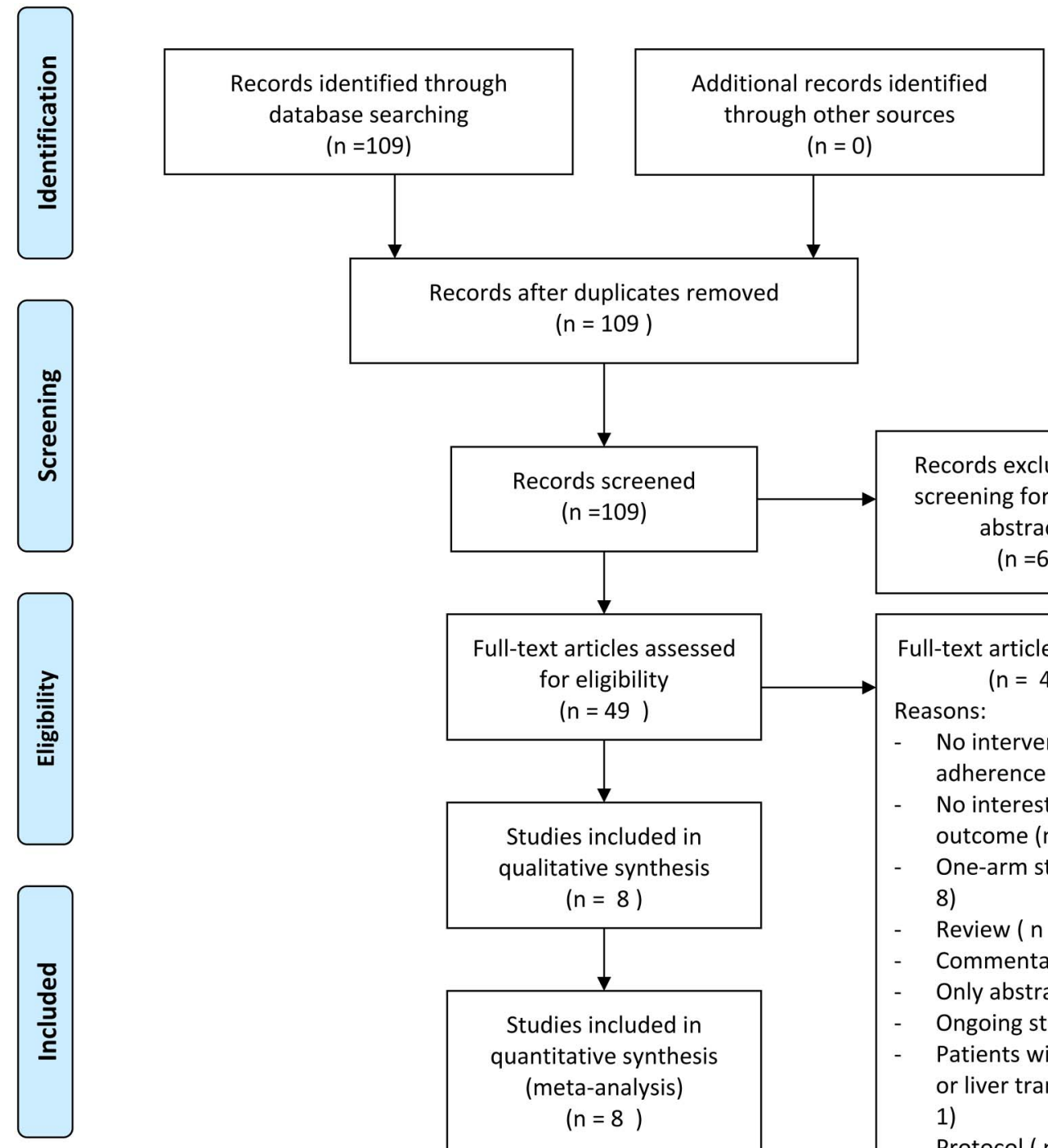

Records excluded after screening for titles and abstractes $(\mathrm{n}=60)$
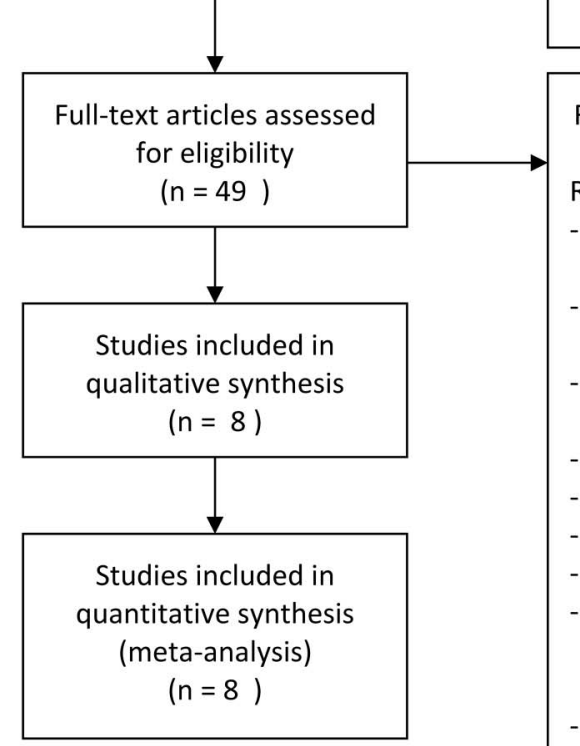

Full-text articles excluded ( $n=41$ )

Reasons:

No intervention for adherence $(n=13)$

- $\quad$ No interesting outcome $(n=12)$

- One-arm studies ( $\mathrm{n}=$ 8)

- $\operatorname{Review}(n=2)$

- Commentary $(n=2)$

Only abstract $(n=1)$

- Ongoing study $(n=1)$

- Patients with kidney or liver transplant $(n=$ 1)

- $\operatorname{Protocol}(n=1)$

Figure 1 PRISMA flow diagram.

and Russell et al for adherence score) resulted in the loss of the significance of the association, indicating the findings may have been overly influenced by these individual studies (figure 3A, B).

\section{Quality assessment}

We used Cochrane Collaboration's tool for assessing risk of bias in the included studies (figure 4). Six studies had low risk of selection bias in random sequence generation, five studies had low risk of attrition bias, and all included studies had low risk of reporting bias. However, only three studies had low risk of bias in allocation concealment and blinding of outcome assessment. All studies had high risk of bias in blinding of participants and personnel. This was anticipated due to the characteristics of adherence intervention. Overall, the included studies had acceptable quality in random sequence generation, incomplete outcome data, and selective reporting.

\section{DISCUSSION}

Poor adherence to immunosuppressive therapy can negatively impact long-term outcomes in patients with kidney transplant. Outcomes of renal transplants are significantly affected by the ability of the transplant recipient to adhere to a complex and ongoing self-management regimen. This study found that adherence intervention through a pharmacist, intervention groups, or continuing education resulted in significantly increased adherence rate and adherence score compared with patients who did not receive adherence intervention. The findings support the idea that adherence intervention improves adherence to immunosuppressive therapy in patients following kidney transplantation.

The importance of improving non-adherence of patients with renal transplant to immunosuppressive therapy is indicated by the findings of several studies. Butler $e t a l^{6}$ performed a systematic review and meta-analysis that assessed the size of impact of non-adherence on graft failure in 
Table 1 Summary of characteristics of included studies

\begin{tabular}{|c|c|c|c|c|c|c|c|c|}
\hline $\begin{array}{l}\text { First author } \\
\text { (year) }\end{array}$ & $\begin{array}{l}\text { Study } \\
\text { design }\end{array}$ & $\begin{array}{l}\text { Intervention } \\
\text { groups }\end{array}$ & Intervention protocol & $\begin{array}{l}\text { Number } \\
\text { of } \\
\text { patients }\end{array}$ & $\begin{array}{l}\text { Mean } \\
\text { age } \\
\text { (year) }\end{array}$ & $\begin{array}{l}\text { Male } \\
(\%)\end{array}$ & $\begin{array}{l}\text { Immunosuppressive } \\
\text { therapy }\end{array}$ & $\begin{array}{l}\text { Length of } \\
\text { follow-ups }\end{array}$ \\
\hline \multirow[t]{2}{*}{ Bessa $(2016)^{25}$} & $\mathrm{RCT}$ & $\begin{array}{l}\text { Pharmaceutical } \\
\text { care }\end{array}$ & $\begin{array}{l}\text { Pharmacist's contribution } \\
\text { to the care of individuals } \\
\text { to optimize medicines } \\
\text { use and improve health } \\
\text { outcomes }\end{array}$ & 62 & 45.8 & 59.40 & $\begin{array}{l}\text { Tacrolimus, prednisolone, } \\
\text { mycophenolate sodium, } \\
\text { or azathioprine }\end{array}$ & 3 months \\
\hline & & Control & NR & 62 & & & & \\
\hline \multirow[t]{2}{*}{ Garcia $(2015)^{32}$} & $\mathrm{RCT}$ & $\begin{array}{l}\text { Continuing } \\
\text { education }\end{array}$ & Continuing education & 55 & 46 & 56.40 & $\begin{array}{l}\text { Tacrolimus-92.7\% } \\
\text { Cyclosporine-1.8\% } \\
\text { Mycophenolate-81.8\% } \\
\text { Azathioprine-16.4\% } \\
\text { Prednisone-100\% }\end{array}$ & 12 months \\
\hline & & Control & Standard care & 56 & 49.29 & 62.50 & $\begin{array}{l}\text { Tacrolimus-94.6\% } \\
\text { Cyclosporine- }-0 \% \\
\text { Mycophenolate- } 80.4 \% \\
\text { Azathioprine- } 21.4 \% \\
\text { Prednisone- } 100 \%\end{array}$ & 12 months \\
\hline \multirow[t]{2}{*}{ Joost $(2014)^{31}$} & Prospective & $\begin{array}{l}\text { Intensified care } \\
\text { group }\end{array}$ & $\begin{array}{l}\text { Educational behavior and } \\
\text { technique intervention }\end{array}$ & 35 & 51 & 77.00 & $\begin{array}{l}\text { Cyclosporine A: } 6(17 \%) \\
\text { Tacrolimus: } 29(83 \%) \\
\text { Mycophenolic acid- } \\
\text { sodium: } 7 \text { (20\%) } \\
\text { Mycophenolic acid- } \\
\text { mofetil: } 28 \text { (80\%) } \\
\text { Steroids withdrawal } \\
\text { within the first } 8 \text { days: } 8 \\
(23 \%)\end{array}$ & 1 year \\
\hline & & Control & Standard care & 39 & 54 & 62.00 & $\begin{array}{l}\text { Cyclosporine A: } 7(18 \%) \\
\text { Tacrolimus: } 32(82 \%) \\
\text { Mycophenolic acid- } \\
\text { sodium: } 8 \text { (21\%) } \\
\text { Mycophenolic acid- } \\
\text { mofetil: } 31 \text { ( } 79 \%) \\
\text { Steroids withdrawal } \\
\text { within the first } 8 \text { days: } 7 \\
(18 \%)\end{array}$ & \\
\hline \multirow[t]{2}{*}{$\begin{array}{l}\text { Chisholm-Burns } \\
(2013)^{28}\end{array}$} & $\mathrm{RCT}$ & Intervention group & $\begin{array}{l}\text { Behavior contract } \\
\text { intervention }\end{array}$ & 76 & 52.78 & 56.60 & $\begin{array}{l}\text { Cyclosporine-8 }(10.5 \%) \\
\text { Tacrolimus-68 }(89.5 \%)\end{array}$ & 15 months \\
\hline & & Control & Standard treatment & 74 & 51.32 & 55.40 & $\begin{array}{l}\text { Cyclosporine-7 }(9.5 \%) \\
\text { Tacrolimus-67 }(90.5 \%)\end{array}$ & \\
\hline \multirow[t]{2}{*}{$\begin{array}{l}\text { McGillicuddy } \\
(2013)^{29}\end{array}$} & $\mathrm{RCT}$ & $\begin{array}{l}\text { mHealth } \\
\text { intervention }\end{array}$ & $\begin{array}{l}\text { mHealth system with } \\
\text { reminder via smartphone }\end{array}$ & 9 & 42.44 & 44.40 & NR & 3 months \\
\hline & & Control & Standard care & 10 & 57.6 & 70.00 & & \\
\hline \multirow[t]{2}{*}{ Russell $(2011)^{27}$} & $\mathrm{RCT}$ & $\begin{array}{l}\text { Continuous } \\
\text { self-improvement }\end{array}$ & $\begin{array}{l}\text { Continuous } \\
\text { self-improvement } \\
\text { intervention }\end{array}$ & 8 & 55 & 50.00 & NR & 6 months \\
\hline & & Control & $\begin{array}{l}\text { Attention control } \\
\text { management }\end{array}$ & 7 & 44 & 42.90 & & \\
\hline \multirow[t]{2}{*}{$\begin{array}{l}\text { Chisholm-Burns } \\
(2001)^{28}\end{array}$} & $\mathrm{RCT}$ & $\begin{array}{l}\text { With clinical } \\
\text { pharmacist } \\
\text { interaction }\end{array}$ & $\begin{array}{l}\text { Clinical pharmacist- } \\
\text { patient interaction over } \\
\text { the telephone }\end{array}$ & 12 & 49.2 & 75.00 & $\begin{array}{l}\text { Cyclosporine-8 }(10.5 \%) \\
\text { Tacrolimus-68 }(89.5 \%)\end{array}$ & 1 year \\
\hline & & Control & NA & 12 & & & $\begin{array}{l}\text { Cyclosporine-7 }(9.5 \%) \\
\text { Tacrolimus-67 }(90.5 \%)\end{array}$ & \\
\hline \multirow[t]{2}{*}{ Fennell $(1994)^{30}$} & Prospective & $\begin{array}{l}\text { Family-based } \\
\text { interventional } \\
\text { program }\end{array}$ & $\begin{array}{l}\text { Family-based } \\
\text { interventional program } \\
\text { with booklet and } \\
\text { calendar }\end{array}$ & 14 & 12 & 57.10 & $\begin{array}{l}\text { Azathioprine and } \\
\text { Prednisone } \\
\text { Cyclosporine }\end{array}$ & NR \\
\hline & & Control & Standard care & 15 & & 60.00 & & \\
\hline
\end{tabular}

NR, not reported; RCT, randomized controlled trial.

patients with renal transplant. Their study included 36 studies. They found that non-adherence was common. For example, in cross-sectional studies, $22.3 \%$ of patients were non-adherent. Butler et al found that the odds of graft loss increased sevenfold in non-adherent subjects. Another study by Feldman $e t a l^{33}$ found patients missed about 4\% of days of immunosuppressive therapy, $36 \%$ missed $\geq 4$ consecutive doses, and that $16 \%$ missed $\geq 10$ consecutive doses over a 2-month study period. Michelon $e t a l^{34}$ found an increasing rate of graft loss due to non-adherence over 
A Adherence rate

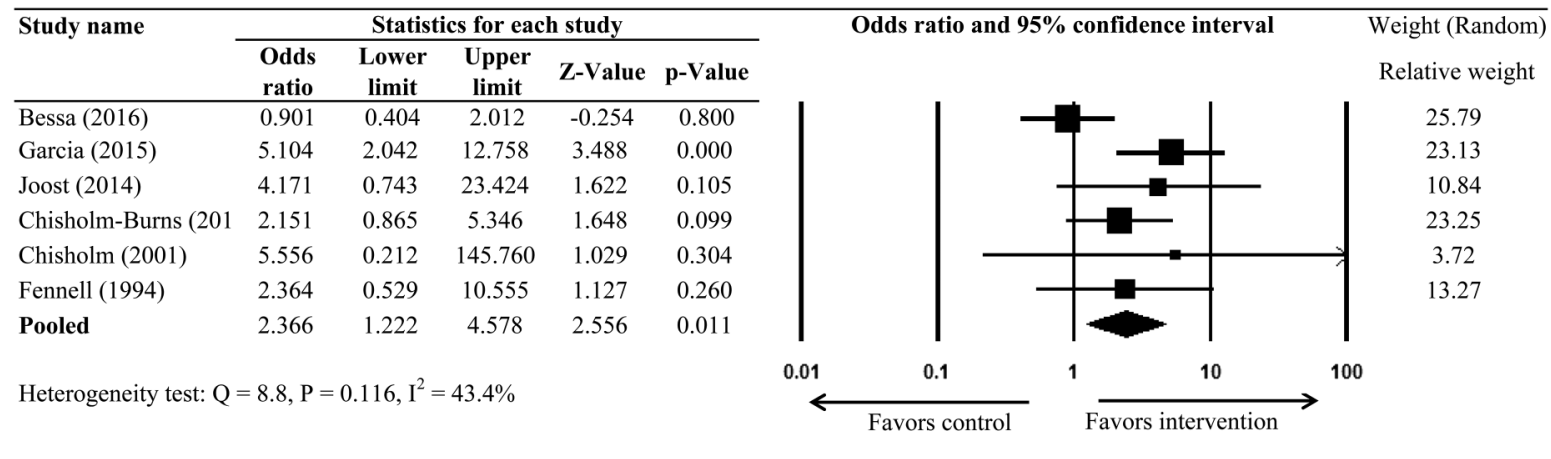

B Adherence score

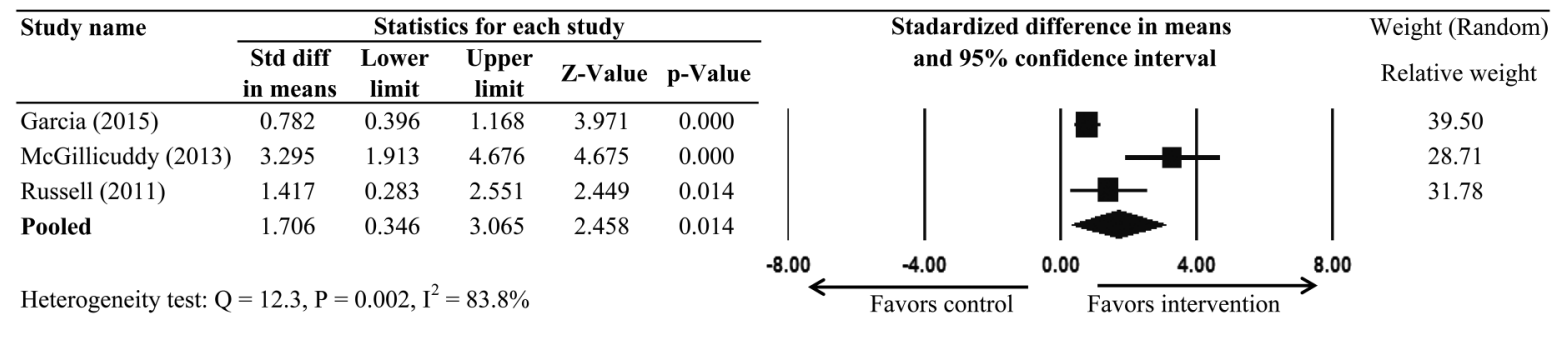

Figure 2 Forest plots for effect of intervention on (A) adherence rate and (B) adherence score.

\section{A Adherence rate}

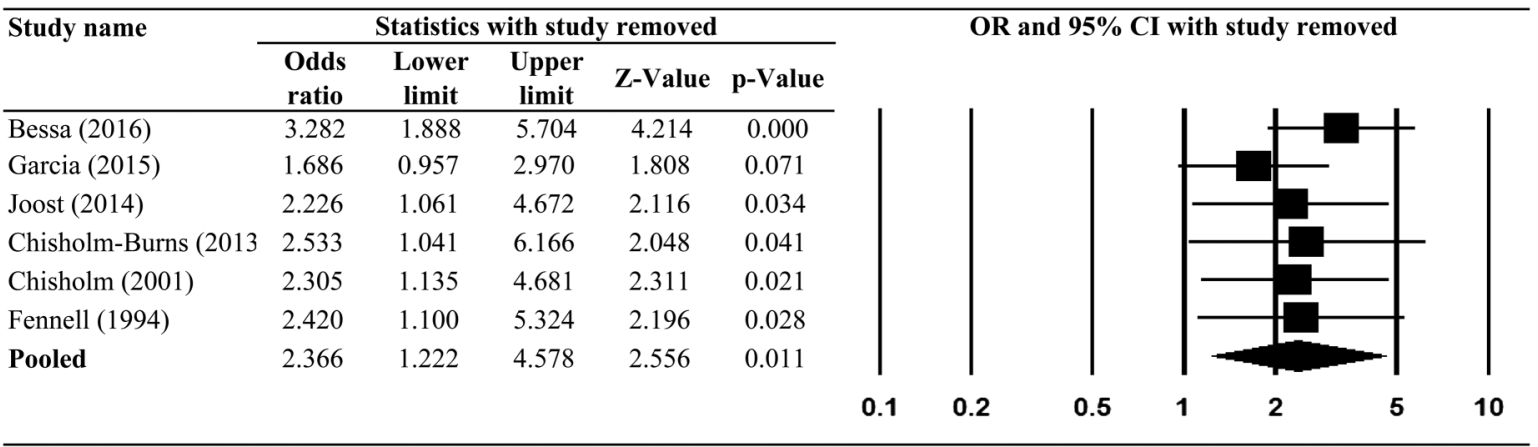

\section{B Adherence score}

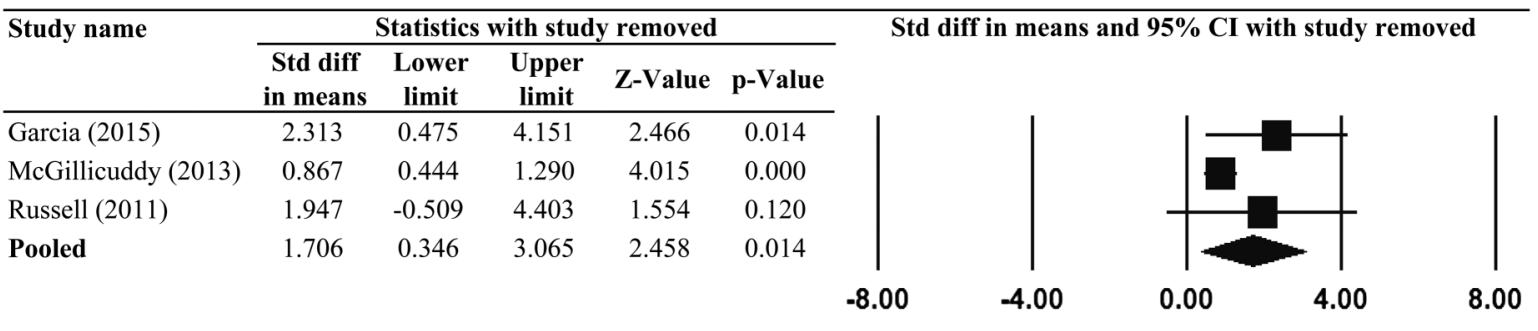

Figure 3 Sensitivity analysis for effect of intervention on (A) adherence rate and (B) adherence score.

three consecutive time periods, suggesting that the effect of non-adherence on graft loss rises over time.

Two studies evaluated the effect of different adherence intervention methods on adherence in patients following kidney transplants. Hardstaff et $a l^{35}$ evaluated the use of smart top bottles compared with pill counting on adherence. ${ }^{35}$ Smart top bottles have a cap with a microprocessor that records the date and time each time the bottle is opened. Patients also received regular structured interviews with a nurse practitioner. Hardstaff et al found smart tops 
Figure 4 Quality assessment.

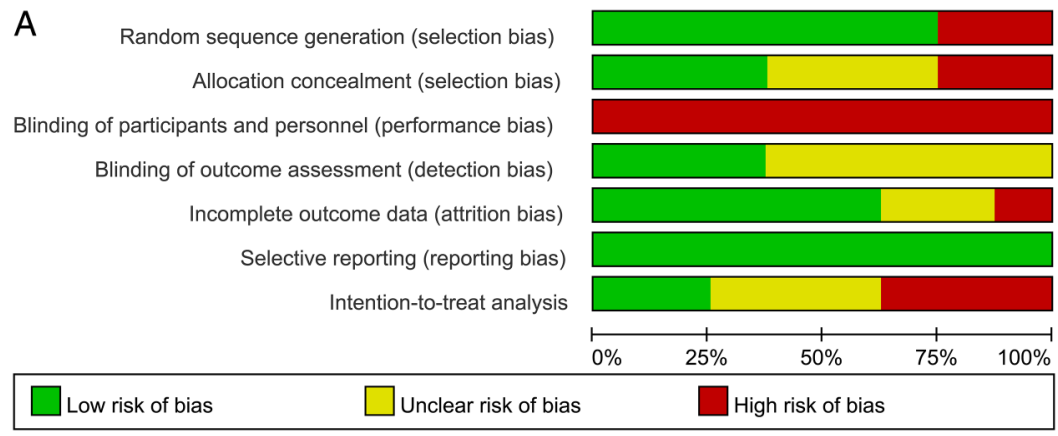

B

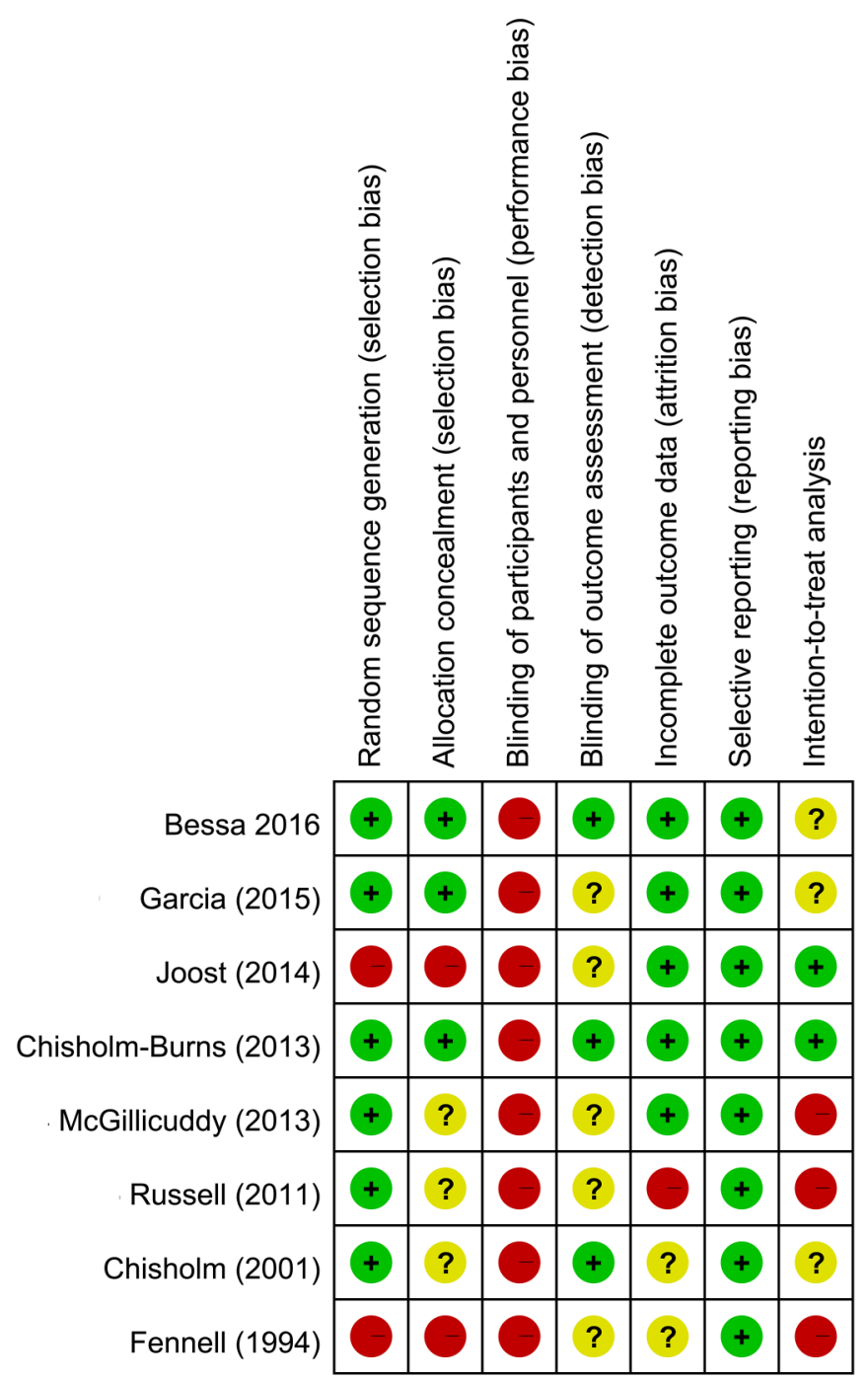

(electronic monitoring) and regular structured interviews were better at determining the number of doses taken, but non-adherence was still high and did not differ between groups ( $46 \%$ of patients in both groups missed at least one dose). In another study, Hardstaff et $a l^{36}$ evaluated the efficacy of electronic monitoring feedback on adherence. All patients were given bottles with smart tops, but only one group was given feedback as measured via the smart top on their adherence at the first clinic visit (range 2-6 months following start of the study). Patients were followed for
12 months. They found no difference between the feedback and control groups with respect to adherence; at 12 months for both groups adherence worsened in about $40 \%$ of patients.

Several self-management strategies are used by patients with renal transplant to help improve adherence. Cedillo-Galindo and Gracida ${ }^{37}$ found that the most common strategies to help improve adherence were use of a cell phone alarm (15.3\%), use of alarm clocks (9.0\%), schedules (5.6\%), taking drugs at meals (5.1\%), using a 
drug record book (2.3\%), and making the medication visible on the table $(2.3 \%)$. A systematic review found kidney transplant recipients improve their self-management through achieving mastery and having an awareness of social accountability to the donor and the medical team. ${ }^{22}$ Other factors that help to motivate patients to remain adherent include anxieties regarding rejection, complications, and comorbidities. Barriers to adherence include forgetfulness, fear of immunosuppressive therapy side effects, and inconsistent advice. ${ }^{22}$ Self-management abilities appear to be impacted by patient age, donor type, and financial difficulties. ${ }^{22}$

There are several limitations to the study. The number of studies included was small. In addition, a large degree of heterogeneity in adherence score across studies was observed, which may reflect the diverse size of patient populations among the studies. The mode of adherence intervention also differed among the studies. Owing to the small number of included studies, it was not possible to perform subgroup analysis to evaluate the impact of different intervention programs. Measuring compliance is difficult and in some studies relied on patient recall which may have confounded the results. ${ }^{35}$

In conclusion, adherence intervention significantly improved adherence to immunosuppressive therapy in patients with kidney transplant. Additional studies are necessary to better understand what types of intervention are most effective, and to gain greater insight into the impact of intervention on clinical outcomes.

Contributors YZ1 contributed to the conception and design, acquisition of data, analysis and interpretation of data, drafting of the manuscript, statistical analysis, and literature research. YZ2 contributed to the acquisition of data, drafting of the manuscript, statistical analysis, and literature research. LZ contributed to the acquisition of data. JZ contributed to the analysis and interpretation of data, statistical analysis, and literature research. JL contributed to the conception and design, critical revision of the manuscript: approved the final manuscript and supervised the study; and is the guarantor of integrity of the entire study.

Funding Beijing Municipal Administration of Hospitals Clinical Medicine Development of Special Funding Support, Code: ZYLX201604; and Beijing Talents Fund (No. 2015000021469G234).

Competing interests None declared.

Ethics approval Meta-analysis and systematic review do not involve any ethics approval.

Provenance and peer review Not commissioned; externally peer reviewed.

Open Access This is an Open Access article distributed in accordance with the Creative Commons Attribution Non Commercial (CC BY-NC 4.0) license, which permits others to distribute, remix, adapt, build upon this work noncommercially, and license their derivative works on different terms, provided the original work is properly cited and the use is non-commercial. See: http:// creativecommons.org/licenses/by-nc/4.0/

\section{REFERENCES}

1 United States Renal Data System. Annual data report: epidemiology of kidney disease in the United States. Vol 7. Bethesda, MD: National Institutes of Health, National Institute of Diabetes and Digestive and Kidney Diseases, 2013:289 and 7(2):284

2 Sellares J, de Freitas DG, Mengel M, et al. Understanding the causes of kidney transplant failure: the dominant role of antibody-mediated rejection and nonadherence. Am J Transplant 2012;12:388-99.

3 Low JK, Crawford K, Manias E, et al. A compilation of consumers' stories: the development of a video to enhance medication adherence in newly transplanted kidney recipients. J Adv Nurs 2016;72:813-24.

4 Fine RN, Becker $Y$, De Geest $S$, et al. Nonadherence consensus conference summary report. Am J Transplant 2009:9:35-41.
5 Dharancy S, Giral M, Tetaz R, et al. Adherence with immunosuppressive treatment after transplantation: results from the French trial PREDICT. Clin Transplant 2012;26:E293-9.

6 Butler JA, Roderick P, Mullee M, et al. Frequency and impact of nonadherence to immunosuppressants after renal transplantation: a systematic review. Transplantation 2004;77:769-76.

7 Denhaerynck K, Dobbels F, Cleemput I, et al. Prevalence, consequences, and determinants of nonadherence in adult renal transplant patients: a literature review. Transp/ Int 2005;18:1121-33.

8 Gordon EJ, Prohaska TR, Gallant MP, et al. Adherence to immunosuppression: a prospective diary study. Transplant Proc 2007;39:3081-5.

9 O'Grady JG, Asderakis A, Bradley R, et al. Multidisciplinary insights into optimizing adherence after solid organ transplantation. Transplantation 2010;89:627-32

10 Kimmel SE, Troxel AB. Novel incentive-based approaches to adherence. Clin Trials 2012;9:689-95.

11 Prendergast MB, Gaston RS. Optimizing medication adherence: an ongoing opportunity to improve outcomes after kidney transplantation. Clin J Am Soc Nephrol 2010;5:1305-11.

12 Russell CL, Ashbaugh C, Peace L, et al. Time-in-a-bottle (TIAB): a longitudinal, correlational study of patterns, potential predictors, and outcomes of immunosuppressive medication adherence in adult kidney transplant recipients. Clin Transplant 2013;27:E580-90.

13 Osterberg L, Blaschke T. Adherence to medication. N Engl J Med 2005;353:487-97.

14 Moons P, Vanrenterghem Y, Van Hooff JP, et al. Health-related quality of life and symptom experience in tacrolimus-based regimens after renal transplantation: a multicentre study. Transp/ Int 2003; 16:653-64.

15 Sketris I, Waite N, Grobler K, et al. Factors affecting compliance with cyclosporine in adult renal transplant patients. Transplant Proc 1994:26:2538-41.

16 Schweizer RT, Rovelli M, Palmeri D, et al. Noncompliance in organ transplant recipients. Transplantation 1990:49:374-7.

17 Massey EK, Tielen M, Laging M, et al. Discrepancies between beliefs and behavior: a prospective study into immunosuppressive medication adherence after kidney transplantation. Transplantation 2015;99:375-80.

18 Achille MA, Ouellette A, Fournier $S$, et al. Impact of stress, distress and feelings of indebtedness on adherence to immunosuppressants following kidney transplantation. Clin Transplant 2006;20:301-6.

19 Cukor D, Rosenthal DS, Jindal RM, et al. Depression is an important contributor to low medication adherence in hemodialyzed patients and transplant recipients. Kidney Int 2009;75:1223-9.

20 Gordon EJ, Prohaska TR, Sehgal AR. The financial impact of immunosuppressant expenses on new kidney transplant recipients. Clin Transplant 2008;22:738-48.

21 Demonceau J, Ruppar T, Kristanto $\mathrm{P}$, et al. Identification and assessment of adherence-enhancing interventions in studies assessing medication adherence through electronically compiled drug dosing histories: a systematic literature review and meta-analysis. Drugs 2013;73:545-62.

22 Jamieson NJ, Hanson CS, Josephson MA, et al. Motivations, challenges, and attitudes to self-management in kidney transplant recipients: a systematic review of qualitative studies. Am J Kidney Dis 2016;67:461-78.

23 Cochrane Handbook for Systematic. Reviews of Interventions. Version 5.1.0. (updated March, 2011). The Cochrane Collaboration. Available at: http:// www.mrc-bsu.cam.ac.uk/cochrane/handbook/.

24 DerSimonian R, Laird N. Meta-analysis in clinical trials. Control Clin Trials 1986:7:177-88.

25 Bessa $A B$, Felipe $C R$, Hannun $P$, et al. Concentrations early after kidney transplant. Ther Drug Monit 2016;38:447-55.

26 Chisholm MA, Mulloy LL, Jagadeesan M, et al. Impact of clinical pharmacy services on renal transplant patients' compliance with immunosuppressive medications. Clin Transplant 2001:15:330-6.

27 Russell C, Conn V, Ashbaugh C, et al. Taking immunosuppressive medications effectively (TIMELink): a pilot randomized controlled trial in adult kidney transplant recipients. Clin Transplant 2011;25:864-70.

28 Chisholm-Burns MA, Spivey CA, Graff Zivin J, et al. Improving outcomes of renal transplant recipients with behavioral adherence contracts: a randomized controlled trial. Am J Transplant 2013;13:2364-73.

29 McGillicuddy JW, Gregoski MJ, Weiland AK, et al. Mobile health medication adherence and blood pressure control in renal transplant recipients: a proof-of-concept randomized controlled trial. JMIR Res Protoc 2013;2:e32.

30 Fennell RS, Foulkes LM, Boggs SR. Family-based program to promote medication compliance in renal transplant children. Transplant Proc 1994:26:102-3. 
31 Joost R, Dorje F, Schwitulla J, et al. Intensified pharmaceutical care is improving immunosuppressive medication adherence in kidney transplant recipients during the first post-transplant year: a quasi-experimental study. Nephrol Dial Transplant 2014;29:1597-607.

32 Garcia MF, Bravin AM, Garcia PD, et al. Behavioral measures to reduce non-adherence in renal transplant recipients: a prospective randomized controlled trial. Int Urol Nephrol 2015;47:1899-905.

33 Feldman $\mathrm{HI}$, Hackett M, Bilker W, et al. Potential utility of electronic drug compliance monitoring in measures of adverse outcomes associated with immunosuppressive agents. Pharmacoepidemiol Drug Saf 1999:8:1-14.
34 Michelon T, Dominguez V, Losekan A, et al. Kidney graft failure due to noncompliance. Transplant Proc 1999;31:3031-2.

35 Hardstaff R, Green K, Talbot D. Noncompliance postrenal transplantation: measuring the extent of the problem using electronic surveillance and nurse practitioner interviews. Transplant Proc 2002:34:1608.

36 Hardstaff R, Green K, Talbot D. Measurement of compliance posttransplantation--the results of a 12-month study using electronic monitoring. Transplant Proc 2003;35:796-7.

37 Cedillo-Galindo H, Gracida C. Barriers and strategies for taking medicines in adult patients with renal transplantation. Transplant Proc 2011;43:3364-6. http://dx.doi.or g/10.1016/j.transproceed.2011.09.084 